\title{
Consequences of a translocation between two divergent lineages of the Paratya australiensis (Decapoda:Atyidae) complex: reproductive success and relative fitness
}

\author{
J. H. Fawcett ${ }^{1}$ \\ Australian Rivers Institute, Griffith University, Nathan, Queensland, 4111, Australia \\ D. A. Hurwood ${ }^{2}$ \\ Biogeosciences, Faculty of Science and Technology, Queensland University of Technology, Gardens Point, \\ Brisbane, Queensland, 4001, Australia and Australian Rivers Institute, Griffith University, Nathan, \\ Queensland, 4111, Australia \\ J. M. Hughes ${ }^{3}$ \\ Australian Rivers Institute, Griffith University, Nathan, Queensland, 4111, Australia
}

\begin{abstract}
When 2 populations are mixed for whatever reason, the outcome can be difficult to predict. In 1993, 2 populations of an atyid shrimp (Paratya australiensis:Atyidae) from different subcatchments of the Brisbane River, Queensland, Australia, were mixed as a result of a translocation. At the time, they were thought to represent slightly divergent populations of a single species. However, subsequent molecular analysis showed that they were significantly divergent. An analysis of patterns at one of the sites in 2001 suggested that the translocated lineage might be sending the resident population extinct in one of the streams. Analysis of mitochondrial deoxyribonucleic acid (DNA) and 3 allozyme loci indicated that the explanation for the outcome might be related to asymmetrical hybridization and nonviability of hybrids between resident females and translocated males. We present data for 2002 and an analysis of samples that had been collected prior to the 2001 study, but not analyzed. We tested 3 hypotheses: 1) the translocated genotypes would continue to increase in relative frequency at sites above the translocation site because their site of origin was at higher altitudes, to which they were expected to be better adapted; 2) at intermediate sites, the relative frequency of translocated alleles in juveniles would increase relative to in their parents; and 3) resident genotypes would survive better than translocated genotypes within a generation, especially at lower and intermediate elevations. Translocated genotypes increased extremely rapidly at the most upstream site. Consistent evidence was present for higher relative frequency of translocated alleles in juveniles relative to their parents, both in the generation following the 2001 study and in the pre-2001 samples. With the exception of in the upstream site, translocated genotypes had lower fitness within a generation than resident genotypes. Thus, the translocated genotypes had a higher reproductive success but were less well adapted to their local environment than residents, a situation that decreased population fitness overall. Such an outcome demonstrates a rarely reported effect of translocations and mixing of divergent lineages.
\end{abstract}

Key words: translocations, extinctions, shrimps, reproductive success.

When 2 populations are mixed by whatever mechanism the outcome of the interaction can be difficult to predict. According to Allendorf et al.

\footnotetext{
${ }^{1}$ E-mail addresses: j.fawcett@derm.qld.gov.au

2 d.hurwood@qut.edu.au

3 To whom correspondence should be addressed. E-mail: jane.hughes@griffith.edu.au
}

(2001), 3 outcomes are possible. The first possibility is that the 2 populations will hybridize freely and mate at random, and, if hybrids are equally as fit as parental genotypes, complete introgression between the 2 forms is likely. A second possibility is that hybridization occurs, but, either because hybrids are sterile or they are less fit, introgression does not occur between the 2 populations. Last, hybridization might 
not occur at all, in which case the 2 forms will coexist in the short term and maybe in the long term, depending on whether one has greater fitness than the other in the particular environment. A loose relationship exists between the genetic divergence between the forms and the possibility of hybridization (Mallet 2005). For example, in Heliconius butterflies, races differing from each other by $<2 \%$ in mitochondrial deoxyribonucleic acid (DNA) sequence composition, hybridize freely, whereas species that occasionally hybridize in the wild mostly diverge by 2 to $6 \%$. No hybrids are found between species differing by $>10 \%$.

Understanding the significance of hybridization in nature is important because mixing of previously isolated populations frequently occurs as a result of human interventions, such as translocations and interbasin transfers of water, and because habitat degradation might bring previously isolated populations together (Coyne and Orr 2004). Hybridization has also been proposed to play a major role in the evolution of species, sometimes resulting in reinforcement of reproductive barriers between closely related species (Servedio and Noor 2003). In such cases, it is thought that where hybrids are less fit than parental types, positive assortative mating, which reduces wastage of gametes resulting from mating with the other genotype, can evolve.

In 1993, 2 lineages of a small freshwater shrimp were mixed in an attempt to examine small-scale dispersal patterns among pools within a stream. Allozyme alleles unique to respective populations were used as direct markers (Hancock and Hughes 1999). At the time, the 2 lineages were thought to represent divergent populations of a single species with only moderate divergence between them and a level of differentiation not unexpected among subcatchments for aquatic organisms (Hughes et al. 1995, Hancock and Hughes 1999). Subsequently, it was discovered that this mixing involved lineages that diverged from one another by $\sim 6 \%$ at the mitochondrial cytochrome oxidase c subunit I gene (Hurwood et al. 2003). A recent, more-widespread geographic analysis revealed that the shrimp Paratya australiensis consisted of a species complex containing at least 9 divergent lineages, and the 2 that had been mixed were both widespread in eastern Australia (Cook et al. 2006). One of these lineages, lineage 4 (L4), appeared to be restricted to higher elevation, upland streams, whereas the other lineage, lineage 6 (L6), occurred at lower elevations. This altitudinal difference was particularly noticeable in the northern parts of the distribution.

The site where the mixing took place was naturally inhabited by L6 shrimp and was at an elevation of $\sim 400 \mathrm{~m}$ asl. The source of the translocated L4 shrimps was at an elevation of $520 \mathrm{~m}$ asl. Summer temperatures were consistently 1 to $2^{\circ} \mathrm{C}$ warmer at the lower site than at the upper site (Hancock 1998a). In 2001, samples were taken along the creek where the mixing had occurred and, based on 3 allozyme loci, it was determined that the 2 lineages had not mated at random (Hughes et al. 2003). Only limited evidence of hybridization was found, but a small number of $F_{1}$ and apparent $\mathrm{F}_{2}$ or backcross individuals were identified. The surprising result was that the L4 shrimp from the higher elevation appeared to be sending the local L6 population to extinction (Hughes et al. 2003). Data from mitochondrial deoxyribonucleic acid DNA (mtDNA) also suggested that hybridization was occurring only in one direction because all $\mathrm{F}_{1}$ hybrids had the mtDNA genotype of the translocated L4 shrimp. At that time, $7 \mathrm{y}$ after the mixing had taken place, the translocated alleles had managed to disperse nearly $2 \mathrm{~km}$ upstream of the point of introduction and $\sim 500 \mathrm{~m}$ downstream.

The fact that the translocated shrimp appeared to be out-competing the local individuals was surprising because it was expected that they would be in a less favored habitat, having come from colder, higher elevations to which they probably were better adapted (Kawecki and Ebert 2004). Hughes et al. (2003) suggested that a possible mechanism to explain the rapid reduction in numbers of local shrimp might be that the local females were preferentially hybridizing with translocated males and their subsequent $\mathrm{F}_{1} \mathrm{~s}$ were nonviable (because none were observed in samples), thus wasting their gametes. Furthermore, evidence was found that the reciprocal cross occurred very rarely or also had low viability because the relative frequencies of $F_{1}$ hybrids with $\mathrm{L} 4 \mathrm{mtDNA}$ were much lower than would be predicted from random mating. This mechanism was proposed as the cause of the extremely fast reduction in number of L6 shrimp.

We examined these ideas further by examining the spread of the translocated genotypes after another generation. We expected that they would not spread further downstream because survival would be constrained by high summer temperatures at downstream sites. We hypothesized that translocated genotypes would continue to extend upstream because they would be reaching their preferred habitat, in other words, they would be moving into higher altitudes.

In addition, we tested the hypothesis that mating patterns would cause an increase in frequency of translocated genotypes between generations, but selection should favor local genotypes within gener- 
ations, especially at sites of lower elevation. We analysed this hypothesis in detail for the generation following the Hughes et al. (2003) study. In addition, we analyzed samples that had been collected for $3 \mathrm{y}$ after the initial translocation (Hancock and Hughes 1999) where we had samples of adults and juveniles from pools above and below the site of introduction. These samples enabled us to examine the changes in allele frequencies in the early stages of the mixing before the sampling time of the study by Hughes et al. (2003).

\section{Methods}

The same 11 sites were sampled in our study as had been sampled in the study by Hughes et al. (2003). The sites are numbered from the home pool (BW0), where the initial translocation took place, upstream to the Branch West plus-five pool $(B W+5)$ and downstream to the Branch Creek minus-five pool $(\mathrm{BW}-5)$ (Fig. 1).

In southeast Queensland, Paratya are found mainly in the headwater streams of eastern flowing river systems. They are omnivorous and consume detritus and algae from benthic surfaces. Adults grow to $35 \mathrm{~mm}$ (Williams 1977, Williams and Smith 1979). The average life cycle of $P$. australiensis is $2 \mathrm{y}$, and most females breed in their $2^{\text {nd }} y$ (Williams 1977). Adults demonstrate a positive rheotactic response to water flow and align themselves with the water flow before moving upstream, but overall movement both upstream and downstream is minimal (Hancock and Hughes 1999). The larger-sized individuals are more conditioned to remain in position during periods of high flow. Larvae and juveniles can be washed downstream depending on available protection against influxes provided by their natal pool (Hancock 1998b, Hancock and Hughes 1999).

Sampling of adult Paratya was undertaken in January 2002 after the breeding season was completed (Hughes et al. 2003 sampled in January 2001). Juveniles also were sampled at this time to allow sufficient time for the planktonic larvae to reach juvenile size (Hancock 1998b). Sampling techniques were as described by Hughes et al. (1995). Samples sizes are shown in Figs 2A, B and 3A, B. The historical sampling was done at the same time of year and included both adults and juveniles. However, only the 2 pools immediately above $(B W+1$ and $B W+2)$ and below (BW-1 and $\mathrm{BW}-2)$ the site of introduction were sampled.

To answer the questions posed in our study, 3 main interactions were examined. At each site the differences in genotype frequencies were examined: 1) between 2001 adult and 2002 adult shrimp to determine to what extent the translocated genotype had increased in range, 2) between 2001 juveniles and 2002 adults to test for evidence of differences in fitness with the expectation that relative frequencies of local genotypes would have increased within a generation, and 3) between 2002 adults and their 2002 juvenile progeny to examine changes in genotype frequencies between generations.

\section{Laboratory procedures}

Allozyme electrophoresis was used to identify translocated, resident, and hybrid individuals using the 3 marker loci system of Hughes et al. (2003). The 2 enzymes aspartate amino transferase (international enzyme commission code $[$ IECC] no. $=2.6 .1 .1)$ and peptidase (IECC no. = 3.4.11), were used to identify differences at 3 loci (Aat-1, Aat-2 and Pep-C) using the conditions outlined in Hughes et al. (2003). For the purposes of our study, individuals that were heterozygous at all 3 marker allozyme loci were categorized as $F_{1}$ hybrids, and individuals that were heterozygous at 1 or 2 loci were labelled $F_{n}$. The latter genotypes could have represented $F_{2}$ or $F_{3}$ individuals or backcrosses.

\section{Statistical analysis}

Allozyme data collected in 2001 by Hughes et al. (2003) were compared with data collected during our study in 2002. Analysis of the allozyme data was done using the GENEPOP 3.1d program (Raymond and Rousset 1995). Allele frequencies, $F_{\mathrm{IS}}$ inbreeding coefficients, expected and observed heterozygosities, and exact tests (Guo and Thomson 1992) for deviation from Hardy-Weinberg Equilibrium (HWE) were calculated for all of the sampled sites. Deviations from HWE would be expected if resident and translocated genotypes were not mating at random or if survival of their offspring were lower than other mating combinations.

Pairwise $F_{\mathrm{ST}}$ values were calculated for each site: 1) between the adult populations from 2001 and 2002, 2) between the juvenile populations from 2001 and adult populations from 2002, and 3) between adult and juvenile populations from 2002 (GENEPOP 3.1d) (Weir and Cockerham 1984). Differences in allele frequencies between samples were tested with the exact test of Goudet et al. (1996). The type I error rate was adjusted for multiple comparisons with the Bonferroni correction method (Rice 1989). For each set of comparisons, the critical level was adjusted according to the number of sites being tested. 


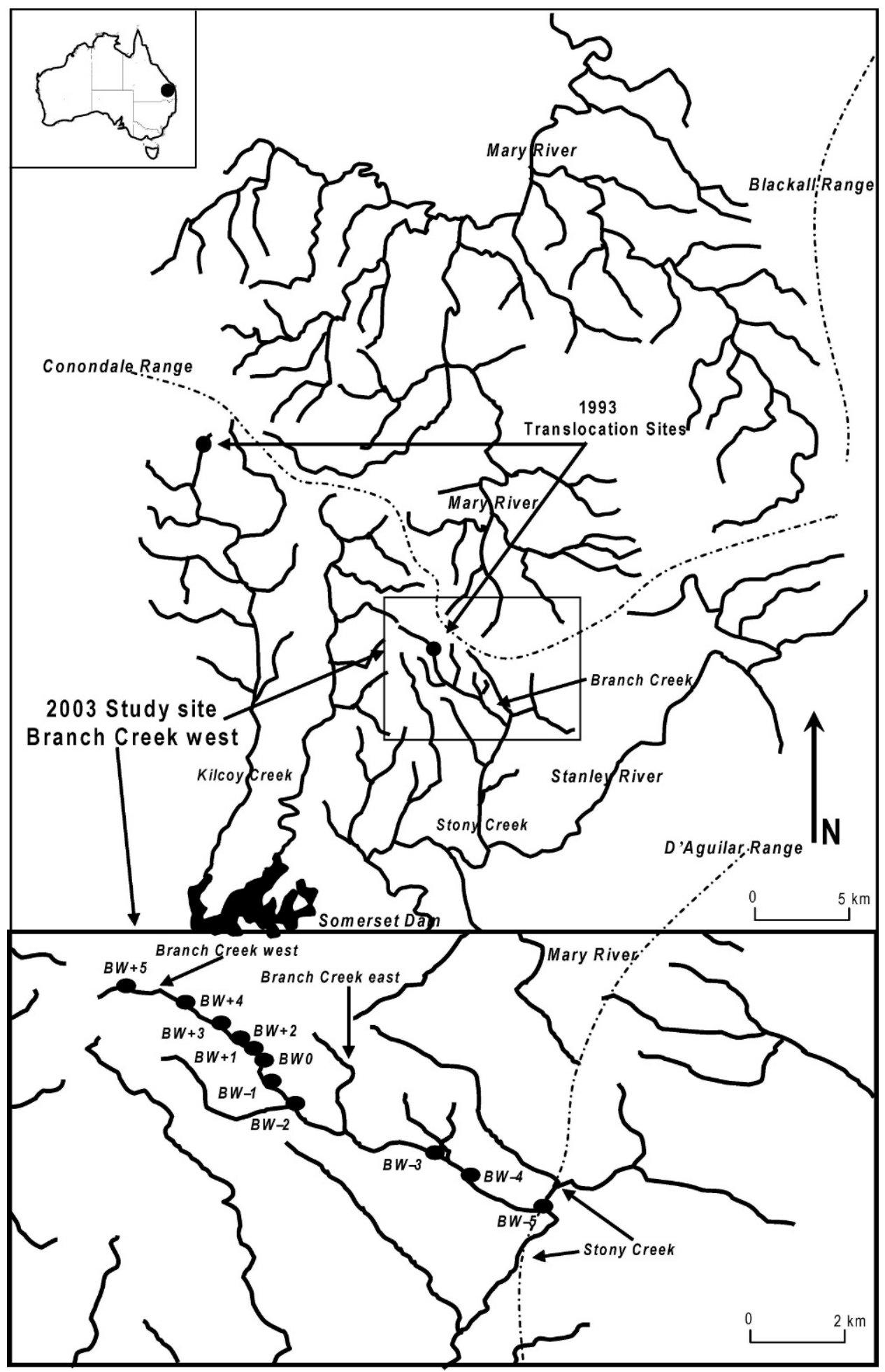

FIG. 1. Branch Creek West study site within the Conondale Range, southeast Queensland, Australia. Sites are numbered from the home pool (BW0), where the initial translocation took place, upstream to the Branch West plus-five pool (BW+5) and downstream to the Branch Creek minus-five pool (BW-5). 


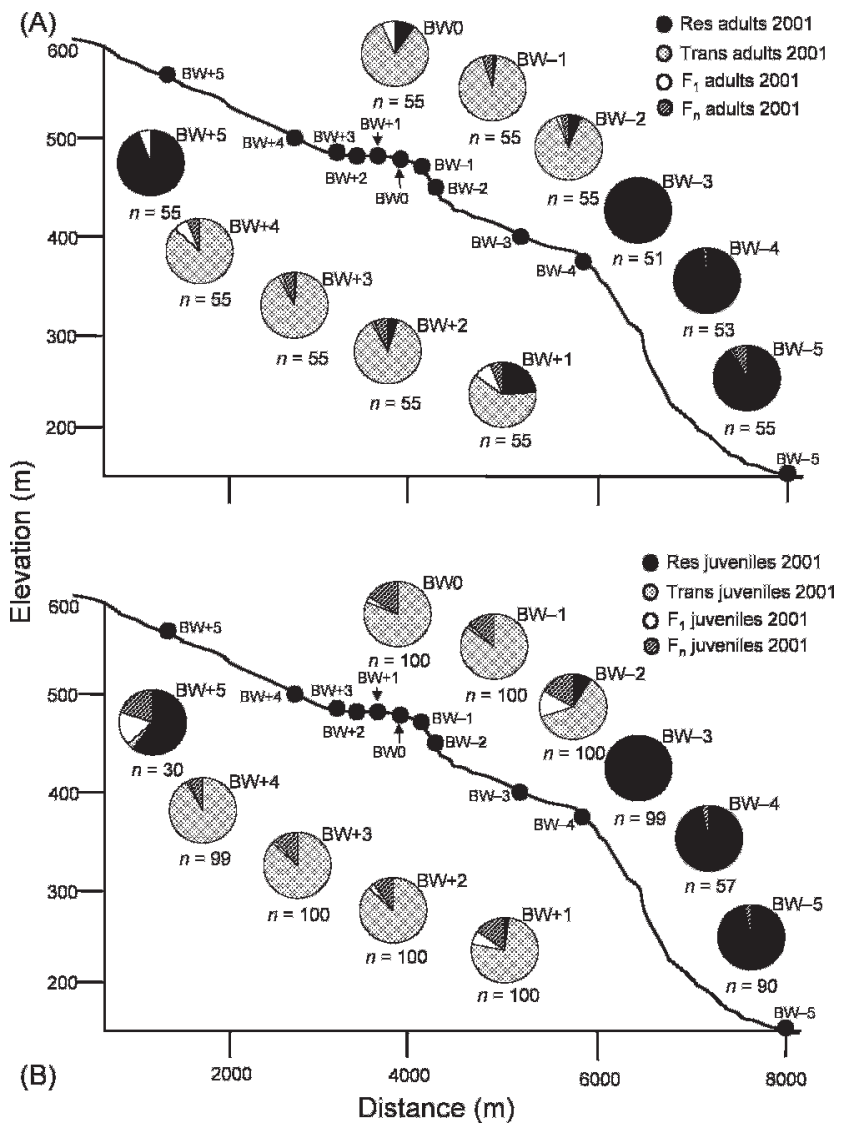

FIG. 2. Stream profiles of Branch Creek showing genotypic frequencies of the resident (res), translocated (trans), $F_{1}$, and $F_{n}$ genotypes for adult (A) and juvenile (B) individuals collected in 2001. See Fig. 1 for an explanation of site labels.

To determine if translocated genotypes had higher fitness than resident genotypes, survivorship, fitness, and selection coefficients were calculated by comparing genotype frequencies of $P$. australiensis juveniles from 2001 with adults from 2002. Each pool could not be treated separately because of low numbers of particular genotypes in each. Therefore, pools BW-2 to $\mathrm{BW}+5$ were combined. Goodness-of-fit $\chi^{2}$ analysis was done on the genotype frequencies to determine if they differed significantly from proportions expected in the absence of selection.

The same 3 loci were analyzed for the old samples (collected 1995-1997). However, only data for Aat-1 are presented here because results were similar for all 3 loci. Frequencies of translocated alleles were calculated in each pool for each time period and with adults and juveniles analyzed separately. This procedure resulted in 5 samples for each of 5 pools, adults from 1995, 1996, and 1997 and juveniles from 1995 and 1996. Fifty-five individuals were analyzed in each sample.

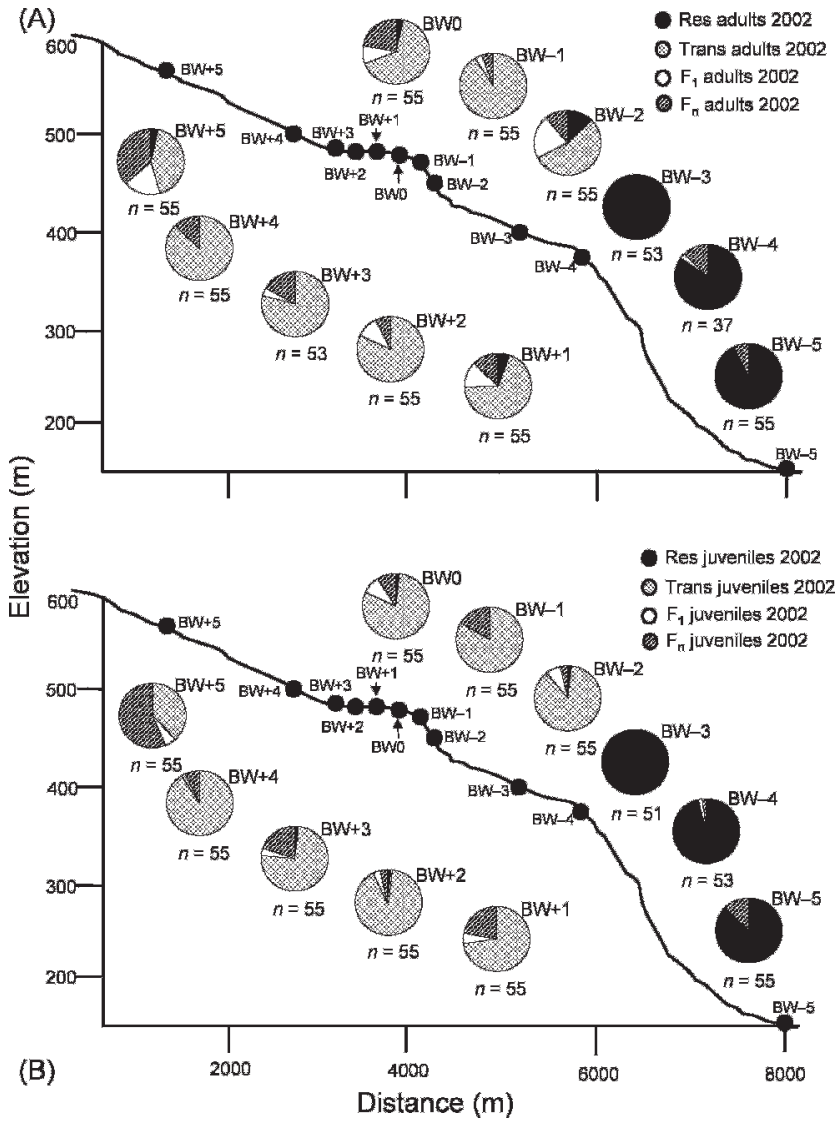

FIG. 3. Stream profiles of Branch Creek showing genotypic frequencies of the resident (res), translocated (trans), $F_{1}$, and $F_{n}$ genotypes for adult (A) and juvenile (B) individuals collected in 2002. See Fig. 1 for an explanation of site labels.

\section{Results}

\section{Comparison of 2001 adults and 2002 adults}

The most surprising result of our study was the absence of resident adult genotypes from 4 of the pools sampled in 2002 (Fig. 3A). Genotypes at sites $\mathrm{BW}-2$ upstream to $\mathrm{BW}+5$ were mainly the translocated genotype. Upstream of BW -3 only sites BW -2 , BW0, BW+1 and BW+5 contained any resident genotypes, albeit in low frequencies. All sites from BW -2 upstream to BW+5 contained hybrid genotypes. Sites $\mathrm{BW}-3, \mathrm{BW}-4$ and $\mathrm{BW}-5$ contained predominantly the resident genotype, with a few hybrid genotypes and no translocated genotypes.

A number of adult samples showed significant deviations from HWE expectations (Table 1). In all cases, the $F_{\text {IS }}$ values were positive indicating a deficiency of heterozygotes. Among juveniles, only 2 samples deviated significantly from expected proportions. Both were in BW+5 (Table 1). After Bonferroni correction, none of these deviations were significant. 
TABLE 1. Results of tests for deviations from Hardy-Weinberg Equilibrium for sampled sites. $p$-values show results of exact

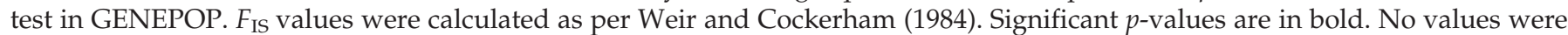
significant after Bonferroni correction. See Fig. 1 for an explanation of pool labels.

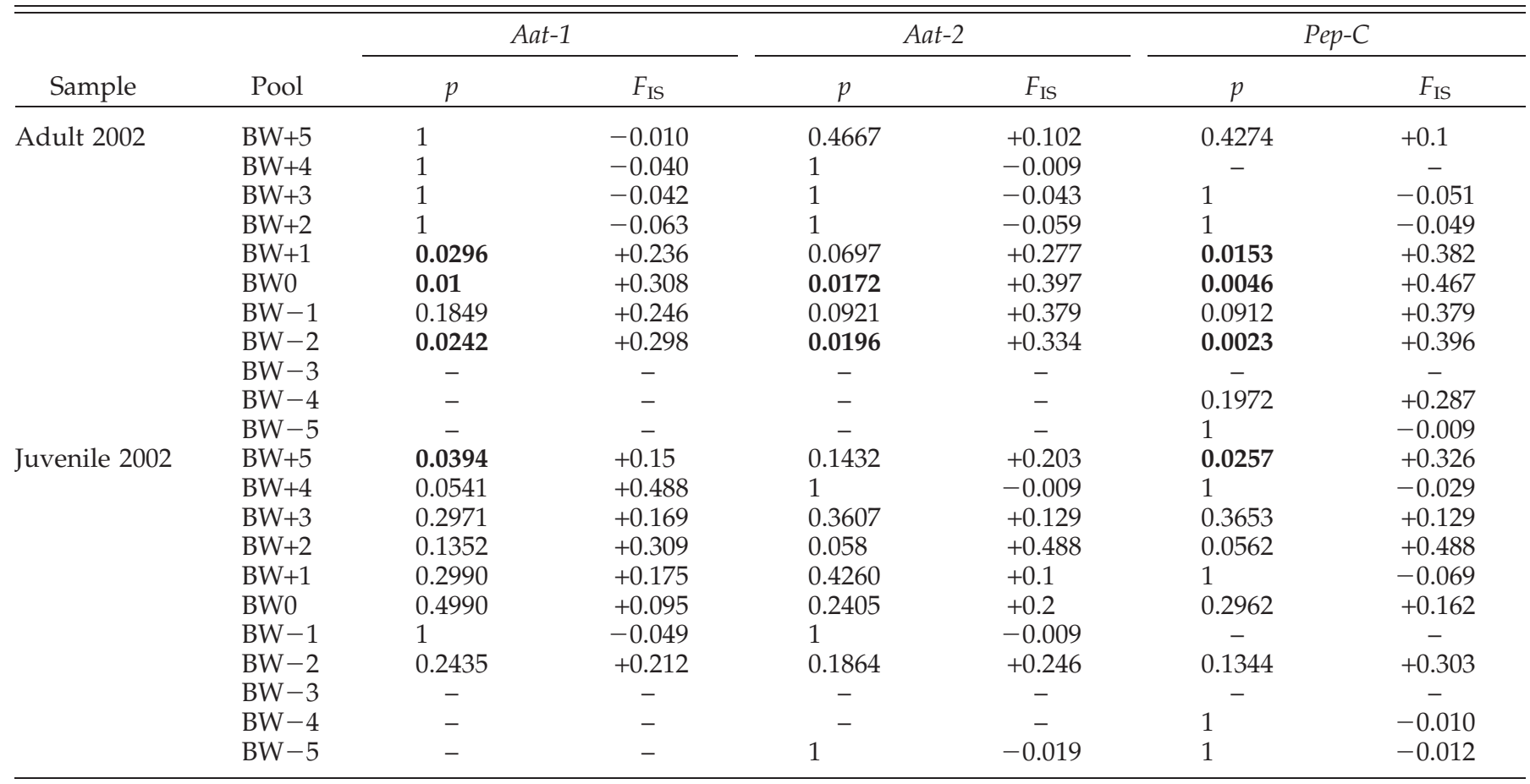

All 3 loci showed almost identical results, so only the results from the Aat-1 locus are shown for comparisons between samples (see Appendices 1, 2 for analyses of Pep-C and Aat-2). The largest difference between 2001 and 2002 adults occurred in BW+5, where the translocated allele increased in frequency while the once dominant resident allele occurred in $\sim 2 \%$ of the sampled adults $\left(F_{\mathrm{ST}}=0.668, p<0.001\right.$; Table 2). In the other pools from BW+4 downstream to $\mathrm{BW}-2$, changes in allele frequency between years were very small, and none were significant after Bonferroni correction.

\section{Comparison of 2001 juveniles and 2002 adults}

When allele frequencies were compared between juveniles in 2001 and adults in 2002 (Figs 2B, 3A), the most significant differences occurred in $\mathrm{BW}+5$, where the translocated allele increased in frequency while the once dominant resident allele within the 2001 juveniles was reduced to occurring in $\sim 2 \%$ of the sampled 2002 adults $\left(F_{\mathrm{ST}}=0.521, p<0.001\right.$; Table 2$)$. All 3 loci showed almost identical results, so only the results from the Aat-1 locus are shown. In BW+4 downstream to $\mathrm{BW}-2$, the translocated allele mostly increased or remained stable. The only significant increases occurred in $\mathrm{BW}+1$ and BW0 $\left(\mathrm{BW}+1 F_{\mathrm{ST}}=\right.$
0.0145, $p<0.05$; BW0 $F_{\mathrm{ST}}=0.0688, p<0.001$; Table 2). The increases in $\mathrm{BW}+1$ were not significant after correction for multiple tests.

Because the pattern in BW+5 differed so strongly from that of the other pools, survivorship, fitness, and selection coefficients were calculated first with data

TABLE 2. $\quad F_{\mathrm{ST}}$ values calculated from Aat-1 data. Other loci gave almost identical values. $\mathrm{A}=$ adult, $\mathrm{J}=$ juvenile. Bold indicates statistical significance. ${ }^{*}=p<0.05,{ }^{* *}=p<0.5$ after Bonferroni adjustment. See Fig. 1 for an explanation of pool labels.

\begin{tabular}{|c|c|c|c|c|c|c|}
\hline \multirow[b]{2}{*}{ Pool } & \multicolumn{2}{|c|}{$\begin{array}{l}\text { A } 2001 \text { vs } \\
\text { A } 2002\end{array}$} & \multicolumn{2}{|c|}{$\begin{array}{l}\text { J } 2001 \text { vs } \\
\text { A } 2002\end{array}$} & \multicolumn{2}{|c|}{$\begin{array}{l}\text { A } 2002 \text { vs } \\
\text { J } 2002\end{array}$} \\
\hline & $F_{\mathrm{ST}}$ & $p$ & $F_{\mathrm{ST}}$ & $p$ & $F_{\mathrm{ST}}$ & $p$ \\
\hline BW+5 & 0.6676 & $* *$ & 0.5214 & $* *$ & -0.0062 & \\
\hline BW+4 & -0.0015 & & 0.0098 & $*$ & -0.0079 & \\
\hline BW+3 & -0.0084 & & -0.0031 & & -0.0052 & \\
\hline BW+2 & -0.0054 & & -0.0022 & & -0.0055 & \\
\hline BW+1 & 0.0453 & ** & 0.0145 & $*$ & 0.0405 & ** \\
\hline BW0 & -0.0124 & & 0.0688 & $* *$ & 0.0119 & \\
\hline $\mathrm{BW}-1$ & -0.003 & & 0.0026 & & 0.0211 & \\
\hline BW -2 & 0.094 & ** & 0.0058 & & 0.1332 & $*$ \\
\hline $\mathrm{BW}-3$ & & & -0.0034 & & & \\
\hline BW -4 & 0.0151 & * & 0.0061 & & -0.0108 & \\
\hline $\mathrm{BW}-5$ & 0.0052 & & & & 0 & \\
\hline
\end{tabular}


TABle 3. Survivorship, fitness, and selection coefficients of each genotype at the Aat-1 locus calculated from data sets that included frequencies from the Branch West plus-five pool $(\mathrm{BW}+5)$ and from data sets that excluded frequencies from $\mathrm{BW}+5$. Trans. $=$ translocated

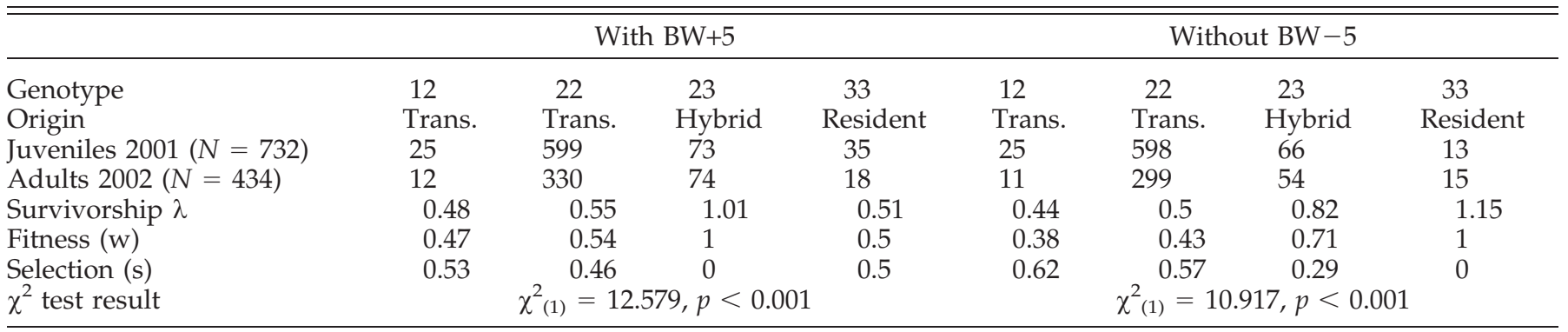

from $\mathrm{BW}+5$ included and then with data from $\mathrm{BW}+5$ excluded for all loci (only Aat-1 results are shown; see Appendices 3, 4 for Pep-C and Aat-2 calculations, respectively). When $\mathrm{BW}+5$ was included, the hybrid genotype had the highest fitness, but when $B W+5$ was excluded, the resident genotype (the '33' genotype in each case) had the highest fitness, and the translocated genotype had the lowest fitness (Table $3, p<0.05$ ).

\section{Comparison of 2002 adults and 2002 juveniles}

Comparison between 2002 adult and juvenile genotypic frequencies (Fig. 3A, B) showed that, as predicted, the number of juveniles with the translocated genotype was higher than the number of adults with the translocated genotype in BW-2 upstream to $\mathrm{BW}+5$, but this difference was significant only in $\mathrm{BW}+1\left(F_{\mathrm{ST}}=0.040, p<0.001\right.$; Table 2$)$ and BW $-2\left(F_{\mathrm{ST}}\right.$ $=0.133, p<0.001$; Table 2). These differences were not significant after correction.

\section{Pre-2001 samples}

A clear pattern emerged when the historical samples were analyzed, especially in BW0, BW +1 , and BW+2 (Fig. 4). The translocated allele increased in frequency both in 1995 and 1996 between adults and juveniles within a year, i.e., the offspring of that year's adults. In contrast, when juveniles of one year were compared with adults in the subsequent year (i.e., representing the same cohort a year later), the frequency of the translocated allele decreased each time. These differences were particularly noticeable in early years, and showed an apparent lag in pools $\mathrm{BW}+1$ and $\mathrm{BW}+2$, probably because translocated genotypes reached these pools later in time.

In the 2 pools downstream of the translocation, the effect was different. Translocated alleles reached BW-2 in 1995 and increased dramatically over 2 y (Fig. 4). At BW-1, the translocated alleles were already established in 1995 and remained relatively constant.

\section{Discussion}

In an earlier study, Hughes et al. (2003) presented evidence that the translocated genotype was having a negative impact on the resident population. The major goal of the current study was to test predictions about further spread of the translocated genotype and to test the hypothesis that mating patterns were favoring the translocated genotype, whereas natural selection was favoring the resident genotype. These predictions were tested by sampling for an additional year and by analysing old samples that had been collected for another project before the effect of the translocation was even suspected. As predicted, the translocated genotypes did not appear to have become established any further downstream in the generation following the 2003 study. Indeed, no translocated genotypes were found below pool BW-3, although a few hybrid genotypes were found in pools $\mathrm{BW}-4$ and $\mathrm{BW}-5$. Temperature tolerance of hybrids might be interme-

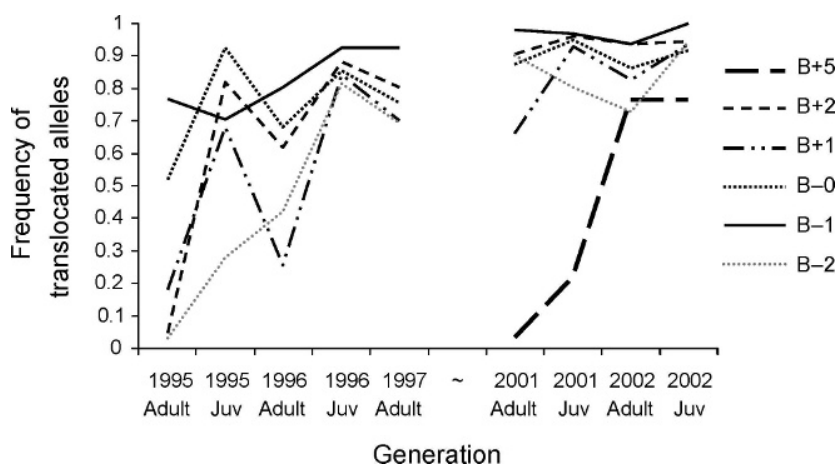

FIG. 4. Frequencies of translocated alleles across years, with adults and juveniles separated. Pools are above $(+)$ and below (-) the site of translocation (BW0) (Fig. 1). Juv $=$ juvenile. 
diate between that of the 2 parental types, thus explaining why hybrid genotypes might manage to survive at downstream sites, whereas pure translocated L4 genotypes appear not to survive. We have no direct physiological data regarding temperature tolerance of the 2 lineages, but a preliminary experiment with 3 tanks of each pure lineage (80 individuals/ tank) was undertaken. Raising temperature by $1^{\circ}$ every $3 \mathrm{~d}$ showed that L6 genotypes consistently survived for longer than L4 genotypes, a result suggesting a greater tolerance to high temperatures in L6 individuals. However, we cannot discount the effects of acclimation because the experimental animals were each taken from their preferred altitude, L4 from Kilcoy Creek and L6 from Branch East, which is the same altitude as Branch West, but contains only L6 shrimps. The fact that the translocated genotypes have not become established further downstream strongly supports the notion that their distribution is limited by habitat. Lineage 4 co-occurs with other lineages of $P$. australiensis in other parts of southeast Queensland (Cook et al. 2006). In 3 coastal streams, where transects have been run along the stream profile, L4 shrimps are always replaced by another lineage at lower elevations $(\sim 200 \mathrm{~m})$, but this elevation varies among streams (Rodriguez 2009).

The alternative possibility, that $\mathrm{L} 4$ shrimps have not managed to reach these sites during the $9 \mathrm{y}$ since the translocation, is extremely unlikely. The species has a planktonic larval stage (Hancock 1998b) so at least some larvae are likely to be washed downstream during high flows. In fact, Hancock (1998a) recorded L4 larvae and juveniles as low as BW-3, even in 1994, only one year after the translocation event. Also, the analysis of 1995 to 1997 samples show clearly that the translocated alleles already were well established in BW -1 by 1995 (frequency of translocated Aat-1 allele $=0.77)$ and had reached BW-2 around 1995 and quickly became established there. Thus, the probability that translocated alleles would have reached the lower pools soon afterwards is high.

The upstream movement and establishment of the translocated genotypes were very rapid. In 2001, no translocated genotypes occurred in the sample of adult shrimps at pool BW +5 , but only 1 y later, translocated genotypes made up nearly $50 \%$ of the total, with $<10 \%$ of individuals having the resident genotype. We had predicted that frequencies of translocated genotypes would continue to increase in upper reaches, but this result was extremely rapid. We suggest that the translocated genotypes are being favored by natural selection both within a generation (they are now in their favored, high altitude habitat) and between generations (see below). The altitude at BW+5 is $580 \mathrm{~m}$ asl, very similar to the altitude of the Kilcoy Creek site from which they originated (520 $\mathrm{m}$ asl). The suggestion that superior competitive powers have enhanced the speed of establishment in this pool also is supported by the fact that when $\mathrm{BW}+5$ is included in the calculation of selection coefficients, the hybrid genotype apparently has highest fitness, whereas when BW+5 is excluded, the resident genotype has the highest fitness. This result would be expected from pooling sites where fitnesses differed, e.g., if translocated genotypes had highest fitness in upper sites, hybrids at intermediate sites, and residents at lower sites. Unfortunately, pools could not be analysed separately because populations in each pool were largely composed of 1 genotype, so numbers of the alternative genotype were too small for statistical analysis.

Another factor that might be contributing to the rapid turnover in $\mathrm{BW}+5$ is that no opportunity existed for any influence of downstream drift by L6 larvae from above because BW +5 was the highest pool in the stream. Furthermore, the population size in this high pool appeared much lower than other pools (hence lower sample sizes), so any new L6 migrants would have had a larger effect on the resident population (Palsbøll et al. 2007).

One slightly puzzling result was the rapid change from adults with mostly the resident and $\mathrm{F}_{1}$ genotypes at BW+5 in 2001 to adults with a large proportion of translocated and $F_{n}$ genotypes in the following generation. A higher frequency of $F_{1}$ genotypes might be expected first, unless selection against them is strong. Alternatively, a significant proportion of the $F_{n}$ genotypes might be colonizers from downstream rather than the product of matings in BW +5 itself.

A striking feature of our results was the almost total disappearance of the resident genotypes from all intermediate sites. Pairwise tests between times were nonsignificant for the most part, and significant cases most often arose from decreases in the frequencies of resident genotypes. Similarly, the predicted differences between adult and juvenile frequencies were not very obvious, mainly because so few resident genotypes were found overall.

The predicted differences between generations were much clearer from the earlier samples, where, particularly at the pools near the translocation site, frequencies of translocated genotypes increased between adults of one generation and juveniles of the next (representing reproductive success of those adults), but decreased between juveniles in one year and adults the next year (representing survival of those juveniles). This result is precisely the ratchet effect that would be expected if translocated genotypes had a higher reproductive success, but lower 
fitness than resident genotypes (Fig. 4). BW+5 is a very clear outlier, where translocated alleles increased dramatically between generations and within one generation as soon as they arrived.

The significance of these results is obvious. It clearly demonstrates the drastic effects that mixing 2 divergent lineages (probably representing cryptic species; Cook et al. 2006) can have on resident populations. The interesting issue here is that it appears that the mating effects of increased reproductive success of translocated genotypes is actually increasing the frequency of genotypes that are less well adapted to their local environment. In other words, the population fitness is reduced overall. This result suggests a $4^{\text {th }}$ possible outcome of mixing populations, in this case the local extinction of both resident and translocated genotypes in the upper reaches of Branch Creek west, that was not proposed by Allendorf et al. (2001). We think it is interesting that the resident genotypes have not been able to restock upstream sites although the resident genotypes appear to have remained in high frequencies in the lower altitude sites (below BW-3). Extinction appears to be a real possibility, given asymmetrical hybridization and reduced fitness of the translocated genotype in Branch Creek conditions. This outcome could be compared to the effects seen in very small populations, where alleles that are actually advantageous can be lost merely through chance drift events (Nunney and Campbell 1993), and overall population fitness goes down. In both cases, alleles that are selectively advantageous are lost, although in the latter case, this is a result of genetic drift, and in the former, it is caused by mating patterns.

The other interesting issue arising from our study is that no evidence was found for the involvement of reinforcement of the reproductive barriers between these 2 species. One might expect that those individuals that did not mate with the translocated genotypes would be strongly favored by selection because the selection against the resident genotypes that hybridize appears to be very strong (Mallet 2005, Servedio and Noor 2003). However, at this stage, no evidence has been found to suggest this process has occurred in any of the pools.

Having observed these effects as a result of artificial mixing of these 2 lineages, we think it is interesting to contemplate whether similar mechanisms operate in this species complex in nature. Cook et al. (2006) showed that many river systems contain $>1$ of these divergent lineages of Paratya. Whether hybrid zones exist between them and whether patterns of asymmetrical mating maintain species boundaries is yet to be examined. The possibility of hybridization between 2 naturally sympatric lineages in the complex, in this case L4 and another lineage, L8, has been investigated in only one published study, from southern Australia. No evidence of hybridization was found in that study even though the 2 lineages were broadly sympatric (Cook et al. 2007). To date, we have not found our 2 lineages, L4 and L6, naturally occurring at the same site.

\section{Acknowledgements}

We thank members of the Molecular Ecology Laboratory at Griffith for discussion about this project and Tim Page and Joel Huey for their efforts with formatting figures.

\section{Literature Cited}

Allendorf, F. W., R. F. Leary, P. Spruell, And J. K. Wenburg. 2001. The problems with hybrids: setting conservation guidelines. Trends in Ecology and Evolution 16:613-622.

Cook, B. D., A. M. Baker, T. J. Page, S. C. Grant, J. H. Fawcett, D. A. Hurwood, AND J. M. Hughes. 2006. Biogeographic history of an Australian freshwater shrimp, Paratya australiensis (Atyidae): the role of life history transition in phylogeographic diversification. Molecular Ecology 15:1083-1093.

Cook, B. D., S. E. Bunn, AND J. M. Hughes. 2007. A comparative analysis of population structuring and genetic diversity in sympatric lineages of freshwater shrimp (Atyidae: Paratya): concerted or independent responses to hydrographic factors. Freshwater Biology 52:2156-2171.

Coyne, J. A., AND H. A. OrR. 1997. Patterns of speciation in Drosophila revisited. Evolution 51:295-303.

Goudet, J., M. Raymond, T. DeMeeus, and F. Rousset. 1996. Testing differentiation in diploid populations. Genetics 144:1933-1940.

Guo, S. W., And E. A. Thompson. 1992. Performing the exact test of Hardy-Weinberg proportion for multiple alleles. Biometrics 48:361-372.

Hancock, M. A. 1998a. Population dynamics and life history of Paratya australiensis Kemp, 1917 (Decapoda: Atyidae) in upland rainforest streams, southeast Queensland, Australia. PhD Thesis, Griffith University, Brisbane, Australia.

Hancock, M. A. 1998b. The relationship between egg size and embryonic and larval development in the freshwater shrimp Paratya australiensis Kemp (Decapoda: Atyidae). Freshwater Biology 39:715-723.

Hancock, M. A., AND J. M. HugHes. 1999. Direct measures of instream movement in a freshwater shrimp using a genetic marker. Hydrobiologia 416:23-32.

Hughes, J. M., S. E. Bunn, D. M. Kingston, And D. A. Hurwood. 1995. Genetic differentiation and dispersal among populations of Paratya australiensis (Atyidae) in rainforest streams in southeast Queensland, Australia. Journal of the North American Benthological Society 14: 158-173. 
Hughes, J., K. Goudkamp, D. Hurwood, M. Hancock, and S. BunN. 2003. Translocation causes extinction of a local population of the freshwater shrimp Paratya australiensis. Conservation Biology 17:1007-1012.

Hurwood, D. A., J. M. Hughes, S. E. Bunn, and C. Cleary. 2003. Population structure in the freshwater shrimp (Paratya australiensis) inferred from allozymes and mitochondrial DNA. Heredity 90:64-70.

KaWeCKI, T. J., AND D. EBert. 2004. Conceptual issues in local adaptation. Ecology Letters 7:1225-1241.

Mallett, J. 2005. Hybridization as an invasion of the genome. Trends in Ecology and Evolution 20:229-237.

Nunney, L., AND K. A. CAmpbell. 1993. Assessing minimum viable population size - demography meets population genetics. Trends in Ecology and Evolution 8:234-239.

Palsbøll, P. J., M. Bérubé, And F. W. Allendorf. 2007. Identification of management units using population genetic data. Trends in Ecology and Evolution 22:11-16.

Raymond, F., AND M. Rousset. 1995. Population genetics software for exact tests and ecumenicism. Journal of Heredity 86:248-249.
Rice, W. R. 1989. Analysing tables of statistical tests. Evolution 43:223-225.

Rodriguez, T. 2009. Interactions between closely related species in the Paratya australiensis species complex. PhD Thesis, Griffith University, Brisbane, Australia.

Servedio, M. R., And M. A. F. Noor. 2003. The role of reinforcement in speciation: theory and data. Annual Review of Ecology and Systematics 34:339-364.

Weir, B. S., and C. C. Cockerham. 1984. Estimating Fstatistics for the analysis of population structure. Evolution 53:1884-1897.

Williams, W. D. 1977. Some aspects of the ecology of Paratya australiensis (Crustacea: Decapoda: Atyidae). Australian Journal of Marine and Freshwater Research 28:403-415.

Williams, W. D., AND M. J. Smith. 1979. A taxonomic revision of Australian species of Paratya (Crustacea: Atyidae). Australian Journal of Marine and Freshwater Research 30:815-832.

Received: 31 July 2009 Accepted: 13 May 2010

ApPENDix 1. $\quad F_{\mathrm{ST}}$ values calculated from Pep-C allele frequencies. Sites are numbered from the home pool (BW0), where the initial translocation took place, upstream to the Branch West plus-five pool $(B W+5)$ and downstream to the Branch Creek minusfive pool (BW-5). $\mathrm{A}=$ adult, $\mathrm{J}=$ juvenile. $^{*}=p<0.05,{ }^{* *}=p<0.001$.

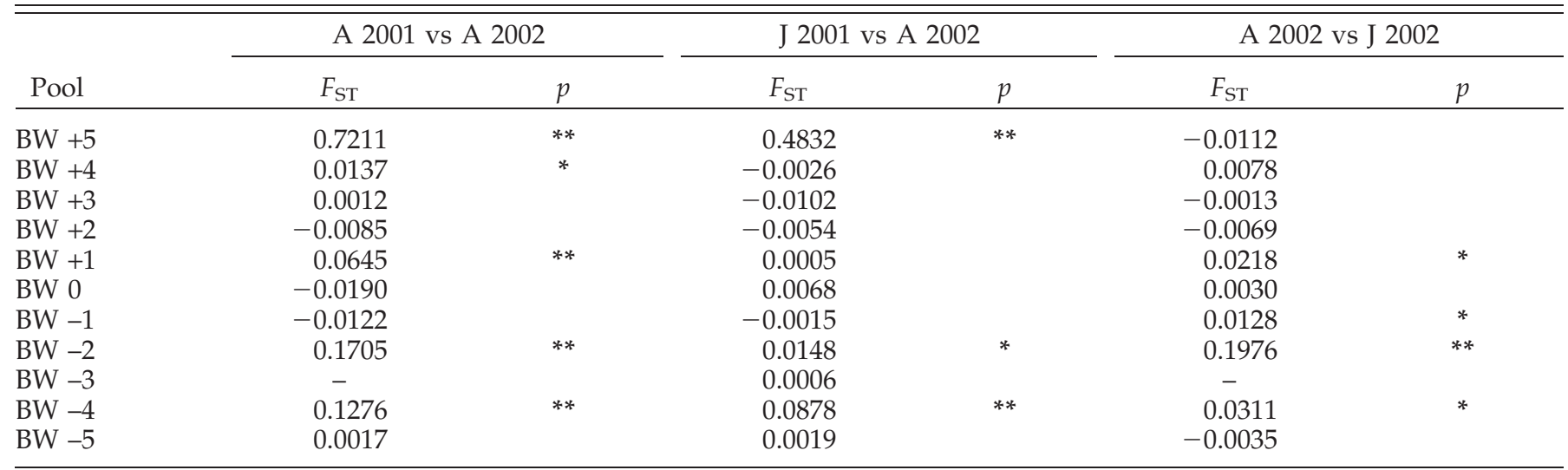


ApPENDIX 2. $F_{\mathrm{ST}}$ values calculated from Aat-2 allele frequencies. Sites are numbered from the home pool (BW0), where the initial translocation took place, upstream to the Branch West plus-five pool $(B W+5)$ and downstream to the Branch Creek minusfive pool (BW-5). $\mathrm{A}=$ adult, $\mathrm{J}=$ juvenile. ${ }^{*}=p<0.05,{ }^{* *}=p<0.001$

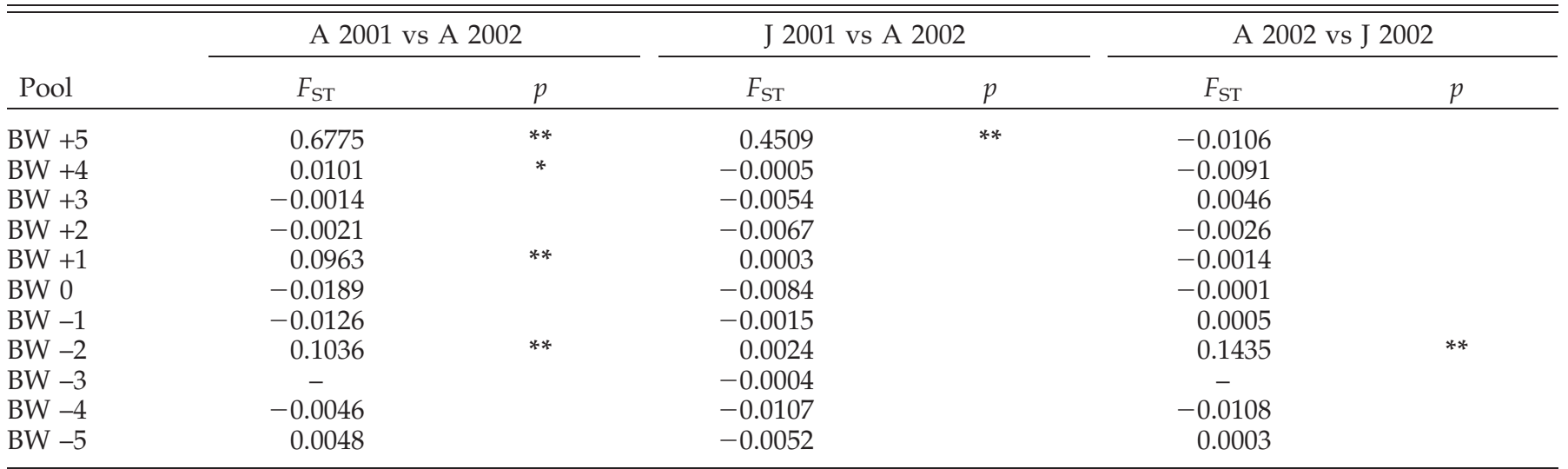

APPENDIX 3. Survivorship, fitness, and selection coefficients for each genotype at the Pep-C locus calculated from data sets that included frequencies from the Branch West plus-five pool $(B W+5)$ and from data sets that excluded frequencies from BW+5. Trans. = translocated.

\begin{tabular}{|c|c|c|c|c|c|c|}
\hline $\begin{array}{l}\text { Variable } \\
\text { Genotype }\end{array}$ & \multicolumn{3}{|c|}{ With BW+5 } & \multicolumn{3}{|c|}{ Without BW+5 } \\
\hline Origin & Trans. & Hybrid & Resident & Trans. & Hybrid & Resident \\
\hline Adult $2002(N=437)$ & 353 & 62 & 22 & 317 & 46 & 19 \\
\hline Survivorship $\lambda$ & 0.56 & 0.92 & 0.7 & 0.5 & 0.78 & 1.58 \\
\hline Fitness $(w)$ & 0.60 & 1 & 0.76 & 0.31 & 0.49 & 1 \\
\hline
\end{tabular}

APPENDIX 4. Survivorship, fitness and selection coefficients for each genotype at the Aat-2 locus calculated from data sets that included frequencies from the Branch West plus-five pool $(B W+5)$ and from data sets that excluded frequencies from $B W+5$. Trans. = translocated.

\begin{tabular}{|c|c|c|c|c|c|c|c|c|}
\hline $\begin{array}{l}\text { Variable } \\
\text { Genotype }\end{array}$ & \multicolumn{4}{|c|}{ With BW+5 } & \multicolumn{4}{|c|}{ Without BW+5 } \\
\hline Origin & Resident & Resident & Hybrid & Trans. & Resident & Resident & Hybrid & Trans. \\
\hline Adult $2002(N=438)$ & 3 & 19 & 66 & 350 & 3 & 15 & 48 & 317 \\
\hline Survivorship $\lambda$ & - & 0.59 & 0.92 & 0.66 & - & 1.07 & 0.76 & 0.60 \\
\hline Fitness $(w)$ & - & 0.64 & 1 & 0.72 & - & 1 & 0.71 & 0.56 \\
\hline
\end{tabular}

